\title{
ФОЛЬКЛОРИСТИКА
}

Научная статья

УДК $001.89+398$

DOI: $10.18101 / 2686-7095-2021-1-75-81$

\section{О РАБОТЕ НАД СЕРИЕЙ «ПАМЯТНИКИ ФОЛЬКЛОРА НАРОДОВ СИБИРИ И ДАЛЬНЕГО ВОСТОКА»: К 90-ЛЕТИЮ А. Б. СОКТОЕВА}

\author{
(C) Кузьмина Евгения Николаевна \\ доктор филологических наук, профессор, \\ главный научный сотрудник сектора фольклора народов Сибири, \\ Институт филологии Сибирского отделения РАН \\ Россия, 630090, г. Новосибирск, ул. Николаева, 8 \\ kuzmina.evgenia2010@yandex.ru
}

\begin{abstract}
Аннотация. Статья посвящена 90-летию Александра Бадмаевича Соктоева - организатора и руководителя коллектива фольклористов Сибири и Дальнего Востока, создающего 60-томную серию образцов фольклорного наследия народов Сибирского и Дальневосточного регионов. Освещаются вопросы: как возникла идея Серии и начиналась работа над ней, с какими трудностями столкнулись сибирские ученые - создатели Серии, в чем заключается заслуга А. Б. Соктоева, стоявшего у истока ее зарождения и своей энергией и талантом вдохновившего, зарядившего ее актуальной, востребованной и сегодня концептуальностью. Утверждается, что успех издательского проекта был заложен в методологии, раскрывающей полифункциональную природу самого фольклора, обосновывающей междисциплинарный и комплексный подход к его образцам. Обращается внимание на то, что каждая подготовленная книга уникальна по своему фольклорному материалу, раскрывающему историю конкретного народа, и в то же время обладает своей историей создания, в которой тесно переплетаются общенаучный и индивидуально-личностный вклад всех подготовивших ее создателей. Ключевые слова: А. Б. Соктоев; Серия; фольклор народов Сибири и Дальнего Востока; междисциплинарный подход.
\end{abstract}

\section{Для цитирования}

Кузьмина Е. Н. О работе над серией «Памятники фольклора народов Сибири и Дальнего Востока»: к 90-летию А. Б. Соктоева // Вестник Бурятского государственного университета. Филология. 2021. Вып. 1. С. 75-81.

В 70-е гг. XX в. сибирские ученые стали обсуждать идею о публикации богатейших собраний фольклорных материалов, которые годами копились поколениями ученых, собирателей, энтузиастов-любителей народного слова во времена активного бытования устного народного поэтического творчества и которые лежали нетронутыми в архивах научных учреждений Сибири.

После широкого обсуждения этой идеи на конференции, состоявшейся в г. Улан-Удэ, было поручено бурятским фольклористам детально ее проработать и результаты этой работы представить на следующей конференции, которая должна была состояться в г. Якутске. С докладом о работе комиссии, проработавшей этапы реализации идеи об издании фольклорных материалов, выступил директор 
Бурятского института общественных наук (ныне ИМБТ СО РАН) доктор филологических наук Василий Цыренович Найдаков. Проект был принят участниками конференции и было решено выйти с ним в Президиум Сибирского отделения CO РАН (тогда СО АН СССР), так как мощь Сибирского отделения как научного центра была известна далеко за пределами страны, да и географическое положение города Новосибирска с удобным транспортным узлом было привлекательно, хотя гуманитарная наука еще отставала от технических, естественно-научных, физико-технических наук, имевших мировые достижения.

С докладом на Президиум СО РАН был направлен доктор филологических наук, тогда ученый секретарь Бурятского научного центра Александр Бадмаевич Соктоев. С присущим ему ораторским талантом и умением убеждать он склонил академиков, далеких от гуманитарных проблем, к решению о необходимости начать издание образцов культурного наследия народов Сибири и Дальнего Востока.

После многих и долгих согласований в необходимых инстанциях идея, наконец, превратилась в реальный крупномасштабный гуманитарный научноиздательский проект, получивший название «Научная подготовка и издание серии "Памятники фольклора народов Сибири и Дальнего Востока" в 60 томах». Многотомная Серия должна была стать академической в деле публикации фольклорных образцов более 30 народов, проживающих в регионе. Предпринималось их издание на двух языках: национальном, с параллельным переводом текстов на русский язык, с сохранением языковых особенностей исполнителей и диалектных различий. Специфика этого издания должна была заключаться в том, что в нем впервые за всю эдиционную практику фольклорные произведения с музыкальной фактурой должны были предстать в нотации. Кроме этого, публикуемые тексты должны были быть снабжены их аудиозаписями. Вот такие нелегкие задачи сразу были поставлены перед создателями Серии.

Волей судьбы и по решению председателя Сибирского отделения РАН Валентина Афанасьевича Коптюга во главе реализации этого проекта был назначен доктор филологических наук Александр Бадмаевич Соктоев. Решение было принято в 1981 г., через два года, в 1983 г., был образован под его руководством сектор фольклора народов Сибири, призванный стать центром подготовки этого широкомасштабного гуманитарного проекта. Сектор со всей энергией, а главное, с глубокой верой в успешное развитие издания начал решать научноорганизационные проблемы, которые сразу же возникли перед Серией в связи с тем, что она по своей научной концепции, задачам, размаху и характеру стала уникальным явлением в мировой гуманитарной науке.

Первым шагом на пути реализации проекта стало создание главной редколлегии Серии, в состав которого вошли ведущие ученые страны, представляющие разные области гуманитарной науки: этномузыковеды Э. Е. Алексеев, И. И. Земцовский, Ю. И. Шейкин, этнографы Б. Н. Путилов, Н. А. Алексеев, фольклористы Х. Г. Короглы, В. М. Гацак, Ю. И. Смирнов, М. И. Тулохонов, лингвист Е. И. Убрятова. Главным редактором стал А. П. Деревянко, его заместителями А. Б. Соктоев и В. М. Гацак, отв. секретарем - Е. Н. Кузьмина.

Выбором верной стратегии на пути реализации Серии стало то, что главная редколлегия с самого начала работы авторских коллективов по подготовке руко- 
E. Н. Кузьмина. О работе над серией «Памятники фольклора народов Сибири и Дальнего Востока»: к 90-летию А. Б. Соктоева

писей снабдила их четкой научной концепцией, содержащей современную методологию междисциплинарного комплексного изучения фольклорного материала. И в помощь им разработала методическое руководство, которое были изложено в брошюре «Принципы и порядок подготовки томов серии “Памятники фольклора народов Сибири и Дальнего Востока"» (1982 г.).

С 1983 по 1990 г. решались полиграфические, издательские, шрифтовые, научные, бюрократические проблемы, которыми щедро был усыпан путь Серии. Именно Александру Бадмаевичу пришлось ходить по различным инстанциям, согласовывать, убеждать, уговаривать, выбивать разрешения на те или иные материалы, начиная с дефицитного тогда финского картона для футляр-упаковок. Они были придуманы заслуженным художником-дизайнером Александром Алексеевичем Рюминым (ныне член-кор. Российской академии художеств) для того, чтобы вкладывать вместе с томом грампластинку, которой должна была снабдиться каждая книга. Эстетическое смысловое оформление футляр-упаковки заключалось ещё и в том, что на каждую из них наносился свой национальный орнамент, каждый раз другой, сколько бы ни было томов в конкретном фольклорном корпусе. Если в бурятском фольклорном корпусе должно быть выпущено семь томов, то и футляр-упаковки к томам представят семь разных орнаментов.

Таким образом, начиная уже с внешнего вида был дан информативный посыл о богатстве и разнообразии декоративно-прикладного искусства народа. Здесь надо отметить, что Александр Бадмаевич обладал настолько яркой харизмой, что мог легко увлечь любого своей идеей и превратить в своего сподвижника. Вот и талантливый А. А. Рюмин сделал такой дизайн Серии, что теперь эти сине-голубые тома под цвет неба, почитаемого всеми народами Сибири, легко узнаваемы и ожидаемы научным сообществом.

Наряду с организационной работой кипела научная подготовка рукописей. С какой неистовой энергией работал сам Александр Бадмаевич, такую же самоотдачу он требовал от своих сотрудников в организованном им секторе. Перед авторскими коллективами была поставлена задача в кратчайшие сроки провести работу по отбору лучших фольклорных образцов в имеющихся фондах и представить в сектор фольклора первичные рукописи. От сотрудников сектора, пока еще малочисленного тогда состава, требовалась самоотверженная работа по подготовке этих рукописей и доведению их до готового издательского вида.

На огромном подъеме и в едином порыве работали все авторы-составители, задействованные в подготовке Серии. От них требовался сформированный корпус текстов на национальном языке с подстрочным переводом их на русский язык, с комментариями «темных мест» в текстах, которые были бы непонятны иноязычному читателю. Уже в секторе плечом к плечу вместе с составителями рукописей редакторами выверялась каждая строка перевода, которая соотносилась с национальным произведением, пополнялись комментарии, расширялся научно-справочный аппарат рукописей томов. Одновременно подбирались орнаменты для футляр-упаковок, фотоиллюстрации, наглядно представляющие те материальные артефакты, о которых говорилось в публикуемых текстах.

И с 1990 г. начался планомерный выход томов в свет. О выходе первого тома «Эвенкийские героические сказания» А. Б. Соктоев написал в великолепной статье, опубликованной в газете «Наука в Сибири» [1]. Поскольку за время подго- 
товки организационной части Серии шла работа над рукописями книг, то с получением возможности издаваться одновременно был готов к выходу из печати ряд томов. Спонтанно они были сформированы в циклы по девять книг. Так, в первом цикле представлены тома эвенкийского, бурятского, якутского эпосов, бурятские, русские, тувинские сказки и несказочная проза саха (якутов). Во втором цикле увидели свет второй том якутского эпоса, тувинские, алтайские, хакасские, шорские сказания, а также русский календарно-обрядовый фольклор, русские лирические песни и фольклор удэгейцев (тома названы в порядке их публикации). В самый разгар работы над Серией не стало Александра Бадмаевича, он принял участие в подготовке первых 18 томов.

Но какой энергией и талантом сибирских ученых, стоявших у истока зарождения идеи Серии, и прежде всего инициатора и первого ее организатора А. Б. Соктоева, заряжена Серия, что она и сегодня остается актуальной, на много лет вперед опередившей своей научной концепцией постулируемый сегодня в науке междисциплинарный и комплексный подход! Успех Серии был с самого начала заложен в ее методологии, раскрывающей полифункциональную природу самого фольклора, который проявляется в жизни через слово, музыку, действие.

В настоящее время опубликовано 34 тома. В редподготовке находятся 16 рукописей, из которых готовы к сдаче следующие три тома: «Алтайские народные песни», «Бурятские героические сказания», «Мифы и сказки хантов». Каждая готовящаяся книга требует особого подхода, обладает своей историей, в которой тесно переплетаются научные и личные представления всех подготовивших ее создателей. Каждый том содержит свою «изюминку», обусловленную самими фольклорными образцами, раскрывающими историю конкретного народа. Публикуется разный фольклорный материал, к подаче которого порой необходимы нетривиальные подходы.

Серия идет в ногу со временем. В ней активно задействованы возможности компьютерных и мультимедиатехнологий, широко используется аудиовизуальная фиксация фольклорного материала. В тома помещаются не только черно-белые, но и блок цветных фотоиллюстраций, создаются фольклорно-этнографические фильмы. Для томов обрядового фольклора готовятся DVD с демонстрацией современных обрядов, проводящихся у народов Сибири. Кроме этого, все опубликованные тома оцифрованы и выложены на сайтах Института филологии СО РАН и Новосибирской государственной областной научной библиотеки. Эти тома можно листать и слушать аудиозаписи, которые записаны на $\mathrm{CD}$ и приложены к книгам. Это очень важно для расширения читательской аудитории и доступности востребованного материала в условиях падения книжного тиража.

Научная жизнь выдвигает все новые требования. Если в самом начале для сотрудников сектора фольклора была приоритетом подготовка и публикация томов Серии, то теперь, помимо этого, они должны вести самостоятельные научные разработки по линии разных научных фондов, заниматься исследовательской работой, публиковать статьи в высокорейтинговых наукометрических журналах, желательно в зарубежных изданиях I и II квартилей. Между тем известно, что филологическая наука весьма ограничена такими возможностями, по сути, она не располагает такими изданиями. Тома же Серии в нашем случае не могут отра- 
E. Н. Кузьмина. О работе над серией «Памятники фольклора народов Сибири и Дальнего Востока»: к 90-летию А. Б. Соктоева

жаться в научных отчетах как конечный результат, хотя их подготовка является кропотливым и трудоемким занятием.

Тем не менее работа над подготовкой книг Серии продолжается. Как показывает расширение числа монографических исследований, диссертаций, статей в гуманитарной науке, достоверной источниковой базой в них все чаще становятся материалы опубликованных в Серии томов. Со временем, когда все сложнее будет находить фольклор у современных народов, тем востребованнее будут тексты, публикуемые в Серии. Она, единственная в мире, охватывает и представляет миру все крупные фольклорные жанры, функционирующие в «живом» бытовании на сибирско-дальневосточной территории. Тексты подготовлены по единым научно-издательским параметрам и в соответствии с требованиями современной гуманитарной науки, и в этом смысле Серия задала высокую планку для всех последующих изданий этого направления.

Продолжение работы над Серией сегодня связано с недостатком финансирования дорогостоящих комплексных фольклорно-этнографических экспедиций, отсутствием квалифицированных кадров фольклористов в национальных регионах и уменьшением их числа в ведущих гуманитарных центрах.

Тома, которые в своем первичном варианте готовились авторскими коллективами в научных учреждениях и вузах Сибири, уже опубликованы. Яркий пример - том якутского эпоса-олонхо «Кыыс Дэбилийэ», над русским переводом которого работали трое: Н. В. Емельянов, П. Е. Ефремов, С. П. Ойунская, сотрудники Института гуманитарных исследований и проблем малочисленных народов Севера СО РАН (в прошлом Институт языка, литературы и истории) [2]. Каждый из них самостоятельно делал перевод, а затем коллегиально все трое сводили свои варианты перевода, вырабатывая наиболее точный, адекватный оригиналу оптимальный перевод без искажения образного смысла и строя публикуемого поэтического памятника. Такая слаженная работа давала успешный результат. Том увидел свет в 1993 г. Так была под руководством Н. В. Емельянова налажена коллективная работа по всем якутским томам. Из шести томов, составляющих якутский фольклорный корпус, опубликовано пять книг. Близок к завершению шестой том.

Но остались тома, не обеспеченные специалистами, а порой просто носителями исчезающих языков, которые могли бы сделать хотя бы подстрочный перевод отобранных для публикации текстов. Вот один из примеров такой проблемной ситуации. В Институте истории, археологии и этнографии народов Дальнего Востока ДВО РАН трудилась Галина Александровна Отаина, которая была ответственной за подготовку томов «Героические песни нивхов» и «Мифы и сказки нивхов». После ее внезапной кончины осталась черновая рукопись на нивхском языке, работа над которой невозможна из-за отсутствия специалистовфольклористов и знатоков языка и фольклора нивхов, которые могли бы помочь в переводе текстов. И это не единственный пример, когда непосредственные авторы-составители уходят из жизни, а заменить их некем.

Другая проблема осложнена отсутствием внятного алфавита у ранее бесписьменных народов Сибири и Дальнего Востока (хантов, коряков). Эти народы пользуются алфавитом, утвержденным в 30-е гг. XX в. Большую сложность в подаче фольклорных текстов вызывает наличие нескольких диалектов в языке, настолько 
разных, что представители этого народа порой не понимают друг друга. Так, например, у хантов есть такие диалекты, как казымский, среднеобской, шурышкарский, приуральский, относящиеся к западному наречию, и сургутский, вахвасьюганский, составляющие восточное наречие. Для того чтобы сохранить в текстах эти диалекты и перевести адекватно произведение на русский язык, следует по каждому диалекту найти его носителя. Положение усугубляется еще и тем, что в условиях такого языкового разнообразия выпускаются учебники для детей, в которых нет единого написания букв, вследствие чего нарушается их орфоэпия и семантика слов. Нет единого подхода к преподаванию языка и взаимопонимания между специалистами-лингвистами и учителями, поэтому каждый хант пишет так, как ему хочется.

Надо заметить, что общее состояние гуманитарной науки, в которой в последние десятилетия остро ощущается отсутствие притока молодых исследователей, сказывается и на развитии фольклористики в Сибири. Между тем фольклорная ситуация в Сибири складывается так, что стремительно угасают некоторые жанры. Уходят знатоки традиционной культуры и вместе с ними исчезают бесценные образцы, сохранявшиеся на протяжении многих поколений.

Теперь со всей очевидностью становится понятной обеспокоенность сибирских фольклористов, высказанная полвека назад, о скорейшей фиксации и сохранении в виде публикаций фольклорного наследия сибирских народов. Выпукло и емко вырисовывается вклад Александра Бадмаевича Соктоева в это дело, который своим талантом организатора, предвидением ученого сдвинул с места и задал ход такой масштабной идее, как 60-томная академическая серия «Памятники фольклора народов Сибири и Дальнего Востока». Ее научное значение будет возрастать год от года в силу того, что публикуемые в ней произведения становятся единственно достоверным источником в деле изучения традиционной культуры сибирских народов.

Мне посчастливилось оказаться рядом с Александром Бадмаевичем, участвовать в становлении этой уникальной Серии с самых первых ее дней, и поэтому в дни его юбилея, 90-летия со дня рождения, поневоле оглядываюсь назад, заново осмысливая пройденный путь Серии и роль Александра Бадмаевича, ее инициатора и вдохновителя.

В свое время сектор фольклора народов Сибири ИФЛ СО РАН преподнес Национальной библиотеке Республики Бурятия опубликованные тома Серии в знак того, что Национальная библиотека играет большую роль в развитии науки в республике, ведет огромную работу в деле просвещения. А еще эти тома частичка огромной души Александра Бадмаевича, который очень любил Бурятию, долго работал преподавателем Педагогического института (ныне университета), ведущим ученым в Бурятском научном центре до отъезда его в Новосибирск. Он мечтал организовать работу над Серией за два года и вернуться в Бурятию, но работа над Серией требовала постоянного его присутствия, которое растянулось на долгие годы, вплоть до ухода Александра Бадмаевича из жизни в 1998 г.

Национальная библиотека РБ стала инициатором проведения презентации томов Серии в честь 90-летия Александра Бадмаевича и провела на своей площадке замечательное онлайн-мероприятие, в котором приняли участие представители научных, вузовских и общественных организаций Республики Бурятия и сотруд- 
E. Н. Кузьмина. О работе над серией «Памятники фольклора народов Сибири и Дальнего Востока»: к 90-летию А. Б. Соктоева

ники сектора фольклора народов Сибири Института филологии СО РАН (г. Новосибирск). А в Бурятском государственном университете имени Доржи Банзарова уже много лет существует и работает кабинет имени А. Б. Соктоева.

\title{
Лuтература
}

1. Соктоев А. Б. Памятники фольклора народов Сибири и Дальнего Востока // Наука в Сибири. 1991. № 6 (февр.); Филологические чтения памяти А. Б. Соктоева: сборник статей / научный редактор С. С. Имихелова. Улан-Удэ: Изд-во Бурят. гос. ун-та, 2010. С. 142-146. Текст: непосредственный.

2. Якутский героический эпос Кыыс Дэбилийэ. Сказитель Н. П. Бурнашев. Зап. С. К. Дьяконова; подг. текста П. Н. Дмитриева, В. В. Илларионова, Л. Д. Нестеровой; пер. Н. В. Емельянова, П. Е. Ефремова, С. П. Ойунской; вступ. ст. Н. В. Емельянова, В. Т. Петрова / отв. ред. тома С. Ю. Неклюдов. Новосибирск: Наука, 1993. 330 с. (Памятники фольклора народов Сибири и Дальнего Востока). Текст: непосредственный.

Статья поступила в редакцию 24.11.2020; одобрена после рецензирования 28.01.2021; принята к публикации 25.03.2021.

\section{WORK ON THE SERIES «FOLKLORE OF PEOPLES OF SIBERIA AND THE FAR EAST », DEDICATED TO 90th ANNIVERSARY OF A. B. SOKTOEV}

\author{
Evgenia N. Kuzmina \\ Dr. Sci. (Phil.), Prof., \\ Institute of Philology, SB RAS \\ 8 Nikolaeva St., Novosibirsk 630090, Russia \\ kuzmina.evgenia2010@yandex.ru
}

Abstract. The article is dedicated to the 90th anniversary of Alexander Badmaevich Soktoev, the first organizer and leader of the group of Siberian and Far East folklorists who created a 60 -volume series of samples of the folklore heritage of the peoples of the Siberian and Far Eastern region. The article highlights how the idea of the Series arose and the work on it began, what difficulties Siberian scientists encountered, what is the merit of A.B. Soktoev, who inspired the work with his energy and talent. The success of this publishing project is due to methodology that reveals the multifunctional nature of folklore itself, justifying an interdisciplinary and integrated approach to its samples. The author pays attention to the fact that each prepared book is unique in its folklore material, revealing the history of particular people, and at the same time has its own history of creation, in which the general scientific and individual contributions of all creators are closely intertwined.

Keywords: A. B. Soktoev; Series; folklore of the peoples of Siberia and the Far East; interdisciplinary approach.

\section{For citation}

Kuzmina E. N. Work on the Series «Folklore of Peoples of Siberia and the Far East», dedicated to the 90th Anniversary of A. B. Soktoev. Bulletin of Buryat State University. Philology. 2021; 1: 75-81 (In Russ.).

The article was submitted 24.11.2020; approved after reviewing 28.01.2021; accepted for publication 25.03.2021. 